\title{
SOME GENERALIZATIONS AND PROBABILITY VERSIONS OF SAMUELSON'S INEQUALITY
}

\author{
HONGWEi JiN AND JULIO BENÍTEZ
}

Abstract. Several generalizations of Samuelson's inequality are given, including complex data and inequalities concerning random variables in a probability space. The proofs of these generalizations need only a well known result from inner product spaces, namely, Bessel's inequality. Finally we apply these generalizations to locate the eigenvalues of certain matrices and tensors, as well as the complex roots of polynomials.

Mathematics subject classification (2010): 60E15, 15A18, 30C15.

Keywords and phrases: Samuelson's inequality, Bessel's inequality, random variables, location of eigenvalues of matrices and tensors, location of the complex roots of polynomials.

\section{REFERENCES}

[1] A. D. R. Choudary, C. P. Niculescu, Real Analysis on Intervals, Springer, New Delhi, 2014.

[2] S. Hu, Z. HuAnG, C. Ling, L. QI, On determinants and eigenvalue theory of tensors, J. Symbolic Comput., 50, (2013), 508-531.

[3] S. T. JENSEN, The Laguerre-Samuelson inequality with extensions and applications in statistics and matrix theory, M. Sc. Thesis.

[4] H. LAGUERRE, Sur une méthod pour obtenir par approximation les racines d'une équation algébrique qui a toutes ses racines réeles [in French]. Nouvelles Annales de Mathématiques (Paris), 2e Série 19 (1880), 161-171 \& 193-202 [JFM 12:71]. [Reprinted in CEuvres de Laguerre (publiées sous les auspices de l'Académie des Sciences par MM. Ch. Hermite, H. Poincaré et E. Rouché), GauthierVillars, Paris, vol. 1, pp. 87-103 (1898)].

[5] A. D. MAdEn, S. BÜYÜKKÖSE, Bounds for Laplacian Graph Eigenvalues, Math. Inequal. Appl., 15, (2012), 529-536.

[6] L. QI, Eigenvalues of a real supersymmetric tensor, J. Symbolic Computation, 40, (2005), 1302-1324.

[7] P. A. Samuelson, How deviant can you be?, J. Amer. Statist. Asoc., 63, (1968), 1522-1525.

[8] D. TASCI, S. BÜYÜKKÖSE, Bounds for singular values using traces of matrices, Selçuk University Art and Science Faculty, Journal of Science, Konya, 17, (2000), 137-146.

[9] F. Zhang, Matrix Theory, Basic Results and Techniques (2nd edition), Springer. 